\title{
STRATEGI KEPALA SEKOLAH DALAM PEMBINAAN BUDAYA RELIGIUS
}

\author{
Wilda Arif \\ Institut Agama Islam Negeri Palopo \\ E-mail: arifwilda93@gmail.com
}

\begin{abstract}
Abstrak
Penelitian ini bertujuan untuk mengetahui strategi kepala sekolah dalam pembinaan budaya religius di SMP Negeri 13 Palopo, untuk mengetahui upaya kepala sekolah dalam pembinaan budaya religius di SMP Negeri 13 Palopo, untuk mengetahui faktor penunjang dan penghambat kepala sekolah dalam pembinaan budaya religius di SMP Negeri 13 Palopo. Penelitian ini merupakan penelitian kualitatif dengan menggunakan pendekatan pedagogic, pendekatan manajemen, dan pendekatan psikologi. Instrumen penelitian menggunakan panduan wawancara, observasi dan dokumentasi. Data dianalisis melalui reduksi data, penyajian data dan pengambilan kesimpulan. Hasil penelitian ini menunjukkan bahwa strategi kepala sekolah dalam pembinaan budaya religius di SMP Negeri 13 Palopo dalam perspektif manajemen yaitu perencanaan, pengorganisasian, pelaksanaan, pengawasan dan evaluasi terhadap program yang dijalankan. Bentuk upaya kepala sekolah dalam pembinaan budaya religius di SMP negeri 13 Palopo meliputi salat duhur dan duha secara berjamaah, literasi baca al-Quran dan doa bersama sebelum memulai pelajaran, peringatan hari-hari besar Islam, menerapkan 3S (Sipakalebbi, Sipakainge, Sipakatau), dan zikir asmaul husna. Faktor penunjang dalam pembinaan budaya religius di SMP Negeri 13 Palopo ialah adanya kepercayaan orang tua siswa yang tinggi terhadap lembaga sekolah, adanya kerjasama yang baik antara kepala sekolah dan guru dalam mensuport kegiatan-kegiatan sekolah. Adapun faktor penghambatnya adalah kurangnya sarana dan prasarana.
\end{abstract}

Kata Kunci: Strategi Kepala Sekolah, Budaya Religius

\begin{abstract}
The aims of this research are to know what is the strategy of the headmaster in fostering religious culture at SMP Negeri 13 Palopo, to know the effort of the headmaster in fostering religious culture at SMP Negeri 13 Palopo, and to know the supporting factors and hindering factors of headmaster in fostering religious culture at SMP Negeri 13 Palopo. This research is qualitative research which used pedagogic, management, and psychology approaches. The instruments used are interview guide, observation, and documentation. The data analyzed by reduction, data display and conclusion. The result of the research shows that the strategy of the headmaster in fostering religious culture at SMP Negeri 13 Palopo are planning, organizing, implementation, supervision and evaluation toward the program. The headmaster efforts in fostering the religious culture at SMP Negeri 13 Palopo such as take dhuhur and dhuha prayers together, reading al-Qur'an literacy program, pray together before the learning process, celebrating Islamic days, implementaing $3 \mathrm{~S}$ (sipakalebbi, sipakainge, sipakatau), and practicing asmaul huzna zikir. The supporting factor in fostering religious culture at SMP Negeri 13 Palopo are the high trust of the students' parents to the headmaster, the good cooperation between the headmaster and the teachers in supporing the programs at school. The hidering factor is the lack of facilities and infrastructure.
\end{abstract}

Keywords: Strategy of Headmaster, Religious Culture 


\section{0 | Wilda Arif}

\section{Pendahuluan}

Pendidikan merupakan sebuah proses perbaikan untuk menata kehidupan manusia, penguatan, serta menjadi penyempurna terhadap semua kemampuan dan potensi manusia. Pendidikan merupakan sebuah ikhtiar manusia dengan tujuan membina kepribadiannya sesuai dengan nilai-nilai dan kebudayaan yang terdapat dalam masyarakat sesuai harapan bangsa ini. ${ }^{1}$ Sekolah sebagai sebuah organisasi, dimana menjadi tempat untuk mengajar dan belajar serta tempat untuk menerima dan memberi pelajaran, terdapat orang atau sekelompok orang untuk melakukan hubungan kerjasama. ${ }^{2}$ Sekolah didorong untuk memberikan perhatian yang lebih besar terhadap semangat atau jiwa pendidikan, kemampuan menyesuaikan diri dan kemudian terhadap pendidikan keterampilan (vocational) dan karir. Tetapi kesemuanya pada hakikatnya menekankan pada aspek intelektual, sosial, kepribadian atau hasil-hasil pendidikan sekolah yang produktif. ${ }^{3}$

Kepala sekolah sebagai top leader pada suatu sekolah bertanggung jawab terhadap pencapaian sekolah. Tugas utama kepala sekolah sebagai pemimpin adalah mengatur situasi, mengendalikan kegiatan kelompok, organisasi atau lembaga dan menjadi juru bicara kelompok. Dalam rangka melaksanakan tugas dan fungsinya, terutama dalam rangka memberdayakan masyarakat dan lingkungan sekitar, kepala sekolah dituntut untuk mampu berperan ganda, baik sebagai catalyst, solution givers, process helpers, dan resource linker. a. Catalyst, berperan meyakinkan orang lain tentang perlunya perubahan menuju kondisi yang lebih baik, b. Solution givers, berperan mengingatkan terhadap tujuan akhir dari perubahan, c. Proces helpers, berperan membantu kelancaran proses perubahan, khususnya menyelesaikan masalah dan membina hubungan antara pihak-pihak yang terkait, dan d. Resource linkers, berperan menghubungkan orang dengan sumber dana yang diperlukan. ${ }^{4}$

Dalam mengimplementasikan visi dan tujuan kepala sekolah diperlukan strategi yang benar. Dimana strategi adalah "program umum untuk pencapaian tujuan-tujuan organisasi dalam pelaksanaan misi”. Kepala sekolah merupakan pihak yang berperan sangat penting dalam menggerakkan kehidupan sekolah, terutama dalam peningkatan kualitas sekolah. ${ }^{5}$ Kepala sekolah memiliki peran penting dalam menentukan arah tujuan dari sekolah. Salah satu tugas penting kepala sekolah yakni membangun budaya sekolah yang kondusif. Budaya adalah asumsi-asumsi dasar dan keyakinan-keyakinan di antara para anggota kelompok atau

${ }^{1}$ Subadar, Membangun Budaya Religius Melalui Kegiatan Supervisi di Madrasah, (Vol. 1 Nomor 2, Jurnal Islam Nusantara, Juli - Desember 2017), h.193.

${ }^{2}$ Wahyosumidjo, Kepemimpinan Kepala Sekolah, (edisi 1;Cet:2, Jakarta: Raja Grafindo Persada,2001).h.134.

3Wahyosumidjo, Kepemimpinan Kepala Sekolah, h.134.

${ }^{4}$ Mulyasa.Pedoman Manajemen Berbasis Madrasah, (Cet. II; Jakarta: Departemen Agama RI, 2005), h. 21.

5Khairuddin, Strategi Kepala Sekolah Dalam Meningkatkan Kompetensi Profesional Guru Pada Madrasah Aliyah Ruhul Islam Anak Bangsa Banda Aceh, (Vol.11 Nomor 1, Jurnal Tabularasa Pps Unime, April 2014), h. 79. 
organisasi. ${ }^{6}$ Budaya sekolah yang kondusif yakni budaya yang mampu mendorong atau mendukung proses pembelajaran di sekolah seperti budaya kegiatan belajar mengajar di kelas, kegiatan ekstrakurikuler di luar kelas serta tradisi dan perilaku warga sekolah secara kontiniu dan konsisten serta budaya religius sekolah.

Budaya religius tidak hanya bisa dibentuk dari proses pembelajaran yang sifatnya teoritis melainkan harus dipraktekkan dan dibina untuk membentuk menjadi kebiasaan. Melalui pembinaan siswa akan disuguhkan dengan keteladanan kepala sekolah dan para guru dalam mengamalkan nilainilai keimanan, dan salah satunya yang paling penting adalah menjadikan keteladanan itu sebagai dorongan untuk meniru dan mempraktikkannya baik di dalam sekolah atau di luar sekolah. Sikap siswa sedikit banyak pasti akan terpengaruh oleh lingkungan di sekitarnya. ${ }^{7}$ Menurut Kahmad dalam Amru Almu'tasim, kata religius dalam bahasa Arab dikenal dengan kata al-din dan al-milah. Kata al-din sendiri mengandung makna berbagai arti sperti al-mulk (kerjaan), al-khidmat (pelayanan), al-ibadat (pengabdian), al-qahr wa alsulthan (kekuasaan dan pemerintahan), altadzallul wa al-khudu (tunduk dan patuh), al-tha'at (taat), al-islam al-taukid (penyerahan dan mengesakan tuhan). ${ }^{8}$ Kata religius tidak identik dengan kata agama, namun lebih kepada keberagaman. Keberagaman, menurut Muhaimin dkk, lebih melihat aspek yang didalam lubuk hati nurani pribadi, sikap personal yang sedikit banyak misteri bagi orang lain, karena menafaskan intimitas jiwa, cita rasa yang mencakup totalitas ke dalam pribadi manusia. ${ }^{9}$ Religiusitas diartikan sebagai seberapa jauh pengetahuan, seberapa kokoh keyakinan, seberapa pelaksanaan ibadah dan kaidah dan seberapa dalam penghayatan atas agama yang dianutnya. Bagi orang Islam, religiusitas dapat diketahui dari seberapa jauh pengetahuan, keyakinan, pelaksanaan dan penghayatan atas agama Islam. ${ }^{10}$

Menurut Madjid, agama bukan hanya kepercayaan kepada yang ghaib dan melaksanakan ritual-ritual tertentu. Agama adalah keseluruhan tingkah laku manusia yang terpuji, yang dilakukan demi memperoleh ridha Allah swt. Agama, dengan kata lain, meliputi keseluruhan tingkah laku manusia dalam hidup ini, yang tingkah laku itu membentuk keutuhan manusia berbudi luhur (ber-akhlaq karimah), atas dasar percaya atau iman kepada Allah swt dan tanggung jawab pribadi dihari kemudian. Jadi dalam hal ini agama mencakup totalitas tingkah laku manusia dalam kehidupan sehari-hari yang dilandasi dengan iman kepada Allah, sehingga seluruh tingkah lakunya berlandaskan

${ }^{6}$ Nurkolis, Manajemen Berbasis Sekolah, (Cet. II; Jakarta: Grasindo, 2005), h. 200.

${ }^{7}$ Mulyasa, Pedoman Manajemen Berbasis Madrasah, h. 32.

${ }^{8}$ Amru Almu'tasim, Penciptaan Budaya Religius Perguruan Tinggi Islam, (Vol. 3 No. 1, Jurnal Pendidikan Agama Islam Juli-Desember 2016), h. 109.

${ }^{9}$ Muhaimin et.al, Paradigma Pendidikan Islam,(Bandung: Remaja Rosdakarya, 2012), h. 287.

${ }^{10}$ Fuad Nashori dan Rachny Diana Muchram, Mengembangkan Kreativitas dalam Perspektif Islam, (Jogyakarta: Menara Kudus,2002), h. 71. 


\section{2 | Wilda Arif}

keimanan dan akan membentuk akhlak karimah yang terbias dalam pribadi dan perilakunya sehari-hari. ${ }^{11}$

Strategi yang tepat dperlukan dalam proses pembinaan budaya religius. Manajemen strategik adalah suatu seni dan ilmu dari perbuatan (formulating), penerapan (implementing), dan evaluasi (evaluating), kepuasan-kepuasan strategis antara fungsi-fungsi yang memungkinkan sebuah organisasi mencapai tujuan-tujuan di masa datang. ${ }^{2}$ Pearce menyatakan bahwa Manajemen strategi adalah sekumpulan keputusan dan tindakan yang menghasilkan perumusan (formulating) dan pelaksanaan (implementasi) rencana-rencana yang dirancang untuk mencapai sasaransasaran perusahaan. ${ }^{13}$ Sedangkan Nawawi berpendapat Manajemen strategik adalah perencanaan berskala besar disebut (perencanaan strategik) yang berorientasi pada jangkauan masa depan yang jauh (visi), dan ditetapkan sebagai keputusan manajemen puncak (keputusan yang bersifat mendasar dan prinsipil), agar memungkinkan organisasi berinteraksi secara efektif (misi) dalam usaha menghasilkan sesuatu (perencanaan operasional untuk menghasilkan barang atau jasa serta pelayanan) yang berkualitas, dengan dengan diarahkan pada optimalisasi pencapaian tujuan (tujuan strategik) dan berbagai sasaran (tujuan operasional) organisasi. ${ }^{14}$ Lebih lanjut Tangkilisan menyatakan Manajemen strategik adalah sebagai keseluruhan sistem manajemen, dimana didalamnya terkandung formulasi, implementasi dan evaluasi guna mencapai hasil yang realistis dan obyektif. ${ }^{15}$ Bisa disimpulkan bahwa manajemen stratejik merupakan suatu system sebagai satu kesatuan yang memiliki berbagai komponen yang saling mempengaruhi dan bergerak secara bersama-sama kearah yang sama.

Dengan penerapan manajemen stratejik, pimpinan pada semua level termasuk kepala sekolah berinteraksi dalam perencanaan dan implementasi. Ada beberapa manfaat dalam penerapan manajemen stratejik yakni 1) memberikan arah jangka panjang yang akan dituju, 2) membantu organisasi beradaptasi pada perubahan-perubahan yang terjadi, 3) membantu suatu organisasi menjadi lebih efektif, 4) mengidentifikasi keunggulan komparatif suatu organisasi dalam lingkungan yang semakin beresiko, 5) aktivitas pembuatan strategi akan mempertinggi kemampuan organisasi untuk mencegah munculnya masalah di masa mendatang, 6) keterlibatan karyawan dalam pembuatan strategi akan lebih memotivasi mereka pada tahap pelaksanaannya, 7) mengurangi aktivitas yang tumpang tindih, dan keengganan untuk berubah dari karyawan lama dapat dikurangi. ${ }^{16}$

11 Madjid, Pendidikan Agama Islam, (Bandung: PT. Remaja Rosdakarya), h. 13.

${ }^{12}$ Wahyudi, Manajemen Strategik Pengantar Proses Berpikir Strategik, (Jakarta: Binarupa Aksara, 1996), h. 16.

${ }^{13}$ Robinson Pearce, Manajemen Strategik Formulasi, Implementasi dan Pengendalian Jilid 1 (Jakarta: Binarupa Aksara, 1997), h. 20.

${ }^{14} \mathrm{H}$. Hadari Nawawi, Manajemen Strategik Organisasi Non Profit Bidang Pemerintahan,(Yogyakarta: UGM Press, 2000), h. 149.

${ }^{15}$ Hassel Nogi S. Tangkilisan, Manajemen Modern untuk Sektor Public, (Yogyakarta: Balairung, 2003), h. 9.

${ }^{16}$ Agustinus Sri Wahyudi, Manajemen, h. 19. 
Ada beberapa strategi yang dapat diterapkan dalam pembinaan budaya religius di sekolah yakni 1) menganalisi lingkungan baik internal maupun eksternal, lingkungan sosial serta sumber daya kultur, 2) merumuskan strategi yang meliputi penetapan visi dan misi yang menjadi arah pengembangan, tujuan pengembangan, strategi pengembangan, dan penetapan kebijakan, 3) mengimplementasikan strategi meliputi perencanaan program, penganggaran dan prosedur pelaksanaannya, 4) monitoring dan mengevaluasi. ${ }^{17}$ Sedangkan menurut Abdullah Nashih Ulwan cara untuk membina nilai-nilai keagamaan pada peserta didik dapat melalui keteladanan, pembiasaan, nasehat, pengawasan, dan hukuman (sanksi). ${ }^{18}$

Ada beberapa penelitian yang juga membahas tentang stratagi dalam mewujudkan budaya religius pada lembaga pendidikan. Penelitian Junasri menyimpulkan bahwa peran kepemimpinan rektor dalam mewujudkan budaya religius di Unversitas Negeri Makassar sudah sudah sangat baik mengingat tugas kepemimpinan rektor sebagai motor penggerak bagi staf dan juga dosen-dosen dalam menjalankan visi dan misi. ${ }^{19}$ Penelitian Ahmad Suriansyah menyatakan bahwa strategi kepala sekolah dalam membentuk karakter siswa dengan filosofis kepemimpinan, keteladanan, kedisiplinan, kepemimpinan isntruksional, kepemimpinan mutu, serta pemberdayaan guru dan tenaga kependidikan. ${ }^{20}$

Fokus penelitian ini yakni strategi kepala sekolah dalam pembinaan budaya religius perspektif manajemen pendidikan Islam. Adapun deskripsi fokus penelitian yakni 1) strategi kepala sekolah dalam pembinaan budaya religius perspektif manajemen pendidikan di SMP Negeri 13 Palopo, 2) upaya kepala sekolah dalam pembinaan budaya relgius di SMP Negeri 13 Palopo, dan 3) faktor penunjang dan penghambat dalam pembinaan budya religius di SMP Negeri 13 Palopo.

\section{Metode}

Penelitian ini merupakan penelitian kualitatif dengan menggunakan pendekatan pedagogic, pendekatan manajemen, dan pendekatan psikologi. Subjek penelitian ada dua yakni subjek primer yaout suluruh stakeholder di SMP Negeri 13 Palopo dan subjek sekunder yakni dokumen guru, kajian teori, dan karya tulis ilmiah yang relevan. Instrumen penelitian

${ }^{17}$ Gatot Dwi Atmadji dan Widyaiswara, "Peran Kepala Sekolah dalam Pengembangan Budaya Sekolah", diakses 20 September 2019. https://www.academia.edu /6977826/peran kepala sekolah pengembangan budaya sekolah.

${ }^{18}$ Abdullah Nashih Ulwan, الإسلام في نربيةالأولد (Tarbiyatul Aulad Fil Islami (Pendidikan Anak Menurut Islam Kaidah-kaidah Dasar)), Penerjemah, Arif Rahman Hakim, Surakarta Insan Kamil, Juni 2012, h. 160-162.

${ }^{19}$ Jumasri, Kepemimpinan Rektor dalam Mewujudkan Budaya Religius di Universitas Negeri Makassar"(Makassar: UNM; tesis, 2016). h. 21.

${ }^{20}$ Ahmad Suriansyah, Strategi Kepemimpinan Kepala Sekolah, Guru, Orang Tua, dan Masyarakat dalam Membentuk Karakter Siswa,( jurnal Cakrawala Pendidikan, Th. XXXIV, No. 2, Juni 2015), h. 234. 


\section{4 | Wilda Arif}

menggunakan panduan wawancara, observasi dan dokumentasi. Data dianalisis melalui reduksi data, penyajian data dan pengambilan kesimpulan.

\section{Strategi Kepala Sekolah dalam Pembinaan Budaya Religius Perspektif Manajemen Pendidikan Islam}

Strategi yang dilakukan dalam pembinaan budaya religius di SMP Negeri 13 Palopo dilihat dari perspektif manajemen sesuai dengan fungsifungsi manajemen yang meliputi perencanaan, pengorganisasian, pelaksanaan, dan evaluasi program yang dijalankan.

\section{Perencanaan}

Kepala sekolah SMP Negeri 13 Palopo melakukan kegiatan perencanaan dalam pembinaan budaya religius dengan tujuan seluruh warga sekola dapat menjalankan dan melaksanakan kegiatan budaya religius di sekolah. Dalam merencang program kepala sekolah melibatkan siswa, guru dan karyawan dalam memberikan inisiatif. Kepala sekolah kemudian memilih usulan yang dibutuhkan warga sekolah. Kepala sekolah melaksanakan musyawarah untuk membahas ide atau gagasan program yang akan direlisasikan untuk segenap warga sekolah.

\section{Pengorganisasian}

Dalam pengorganisasian kepala sekolah melaksanakan tugas dan fungsinya sebagai manajer pendidikan. Kepala sekolah membagi tugas dan tanggung jawab guru sesuai dengan kompetensi dan bakat yang dimilikinya.

\section{Pelaksanaan}

Kepala sekolah melakukan pembinaan dengan menggorakkan organisasi sesuai dengan pembagian tugas masing-masing serta menggerakkan seluruh seumber daya yang ada dalam organisasi agar pekerjaan atau kegiatan berjalan seseai dengan rencana. Kepala sekolah menggerakkan segala sumber daya yang ada melai dari pemanfaatan waktu yang intensif, sumber daya manusia, penggunaan metode, dan penyediaan peralatan dalam menunjang keberhasilan pembinaan budaya religius.

\section{Pengawasan}

Kepala sekolah melaksanakan proses pengawasan dengan melakukan evaluasi terhdapa kinerja guru yaitu dengan melakukan supervise kelas. Hal ini dilakukan untuk mengetahui apakah guru sudah melaksanaka program dengan benar baik dalam penyampaian program pelajaran, adminisstrasi kelas dan penyampaian materi.

\section{Evaluasi}

Evaluasi yang dilakukan oleh kepala sekolah dalam membina budaya religius adalah untuk mengetahui realisasi perilaku warga sekolah, dan apakah tingkat pencapaian tujuan sesuai dengan apa yang di inginkan, selanjutnya apakah perlu diadakan perbaikan. Oleh karena itu kegiatan evaluasi dimaksudkan untuk mencegah penyimpangan dalam pelaksanaan. Pekerjaan, menilai proses, dan hasil kegiatan, sekaligus untuk melakukan tindakan perbaikan. Dampak keberhasilan pembinaan dapat terlihat pada 1) dampak keberhasilan terhadap siswa, 2) dampak keberhasilan terhadap guru dan karyawan dan, 3) dampak terhadap sekolah. 


\section{Upaya Kepala Sekolah dalam Pembinaan Budaya Religius}

Pembinaan budaya religius di SMP Negeri 13 Palopo merupakan sekolah umum yang berciri khas Islam, hal tersebut dapat dilihat dari budaya sekolah yang mengedepankan budaya agama Islam di dalamnya. Tujuan yang digaungkan adalah meningkatkan kualitas pelaksanaan kegiatan keagamaan. Kepala sekolah sebagai pemimpin harus mampu memberikan petunjuk dan pengawasan meningkatkan kemauan tenaga kependidikan, membuka komunikasi dua arah dan mendelegasikan tugas. Seorang kepala sekolah juga harus mampu menggerakkan anggota organisasinya agar tercapainya sebuah tujuan yang telah direncanakan. Pembinaan budaya religius juga dilakukan dengan memberikan motivasi sehingga nantinya siswa melakukan suatu pekerjaan didasari dengan nilai agama dan muncul dari keinginannya untuk melaksanakan ajaran-ajaran agamanya. Strategi kepala sekolah dalam membina budaya religius di SMP Negeri 13 Palopo terlihat dari kegiatankegiatan yang dilaksanakan seperti salat dhuhur berjamaah, salat dhuha, literai baca al-Qur'an, membaca do'a sebelum proses pembelajaran, menerapkan 3S (sipakatau, sipakainge, siakatau), peringatan hari-hari besar Islam, dan pembcaan asmaul husna setiap hari jum'at.

\section{Faktor Penunjang dan Penghambat dalam Pembinaan Budaya Religius}

Faktor penunjang yang mendukung keberhasilan dari strategi kepala sekolah dalam pembinaan budaya religius di SMP Negeri 13 Palopo yaitu adanya kepercayaan orang tua siswa yang tinggi kepada kepala sekolah dan sekolah dalam melaksanakan setiap program pembinaan. Faktor ini menjadi menjadi kunci trsendiri bagi keberhasilan lembaga sekolah dalam menjalankan program-program sekolah karena mendapat dukungan penuh dari para orang tua siswa. Terjalinnya komunikasi yang baik antara lembaga sekolah dengan orang tua siswa juga menjadi kunci keberhasilan dan menentukan prestasi siswa itu sendiri dalam menjalani kegiatan belajarnya di sekolah. selanjutnya adalah adanya kerjasama yang baik antara kepala sekolah dan guru dalam mensuport kegiatan-kegiatan sekolah. Adapun yang menjadi faktor penghambat dalam pembinaan budaya religius yaitu kurangnya sarana dan prasarana.

\section{Kesimpulan}

Strategi Kepala Sekolah dalam pembinaan budaya religius di SMP Negeri 13 Palopo perspektif manajemen pendidikan yaitu membuat perencanaan, pengorganisasian, pelaksanaan, melakukan pengawasan dan evaluasi terhadap program yang dijalankan. Upaya dalam pembinaan budaya religius di SMP Negeri 13 Palopo yaitu melaksanakan salat duhur secara berjamaah, salat duha, literasi baca al-Quran dan doa sebelum memulai proses belajar mengajar, menerapkan 3S (Sipakalebbi, Sipakainge, Sipakatau), memperingati hari besar Islam, Zikir asmaul husna tiap hari 


\section{6 | Wilda Arif}

jumat. Hal tersebut merupakan kegiatan yang merupakan upaya dalam pembinaan budaya religius yang ada di SMP Negeri 13 Palopo.

Faktor penunjang dan penghambat dalam pembinaan budaya religius yaitu faktor penunjangnya dari keberlangsungan program-program sekolah dalam rangka pembinaan budaya religius di SMP Negeri 13 Palopo adalah kepercayaan orang tua siswa yang tinggi terhadap lembaga sekolah. Faktor ini menjadi kunci tersendiri bagi keberhasilan lembaga sekolah dalam menjalani program - programnya karena mendapat dukungan penuh dari para orang tua siswa. Terjalinnya komunikasi yang baik antara lembaga sekolah dengan orang tua siswa juga menjadi kunci keberhasilan dan menentukan prestasi siswa itu sendiri dalam menjalani kegiatan belajarnya di sekolah. selanjutnya adalah adanya kerjasama yang baik antara kepala sekolah dan guru dalam mensuport kegiatan-kegiatan sekolah. Adapun yang menjadi faktor penghambat dalam pembinaan budaya religius yaitu kurangnya sarana dan prasarana dalam hal ini di sekolah SMP Negeri 13 Palopo belum memiliki mushollah yang layak.

\section{Daftar Pustaka}

Almu'tasim. Amru. 2016. Penciptaan Budaya Religius Perguruan Tinggi Islam, Vol. 3 No. 1, Jurnal Pendidikan Agama Islam Juli-Desember.

Atmadji. Gatot Dwi dan Widyaiswara. "Peran Kepala Sekolah dalam Pengembangan Budaya Sekolah", diakses 20 September 2019. https://www.academia.edu /6977826/peran kepala sekolah pengembangan budaya sekolah.

Jumasri. 2016. Kepemimpinan Rektor dalam Mewujudkan Budaya Religius di Universitas Negeri Makassar", Makassar: UNM; tesis.

Khairuddin. 2014. Strategi Kepala Sekolah Dalam Meningkatkan Kompetensi Profesional Guru Pada Madrasah Aliyah Ruhul Islam Anak Bangsa Banda Aceh, Vol.11 Nomor 1, Jurnal Tabularasa Pps Unime.

Madjid, Pendidikan Agama Islam, Bandung: PT. Remaja Rosdakarya.

Muhaimin et.al. 2012. Paradigma Pendidikan Islam, Bandung: Remaja Rosdakarya.

Mulyasa. 2005. Pedoman Manajemen Berbasis Madrasah, Cet. II; Jakarta: Departemen Agama RI

Nashori. Fuad dan Rachny Diana Muchram. 2002. Mengembangkan Kreativitas dalam Perspektif Islam, Jogyakarta: Menara Kudus.

Nawawi. H. Hadari. 2000. Manajemen Strategik Organisasi Non Profit Bidang Pemerintahan, Yogyakarta: UGM Press.

Nurkolis. 2005. Manajemen Berbasis Sekolah, Cet. II; Jakarta: Grasindo.

Pearce. Robinson. 1997. Manajemen Strategik Formulasi, Implementasi dan Pengendalian Jilid 1 Jakarta: Binarupa Aksara.

Subadar. 2017. Membangun Budaya Religius Melalui Kegiatan Supervisi di Madrasah, Vol. 1 Nomor 2, Jurnal Islam Nusantara. 
Suriansyah. Ahmad. 2015. Strategi Kepemimpinan Kepala Sekolah, Guru, Orang Tua, dan Masyarakat dalam Membentuk Karakter Siswa, jurnal Cakrawala Pendidikan, Th. XXXIV, No. 2.

Tangkilisan. Hassel Nogi S. 2003. Manajemen Modern untuk Sektor Public, Yogyakarta: Balairung.

Ulwan. Abdullah Nashih. 2012. الإسلام في تربيةالأولد (Tarbiyatul Aulad Fil Islami (Pendidikan Anak Menurut Islam Kaidah-kaidah Dasar), Penerjemah, Arif Rahman Hakim, Surakarta Insan Kamil.

Wahyosumidjo. 2001. Kepemimpinan Kepala Sekolah, edisi 1;Cet:2, Jakarta: Raja Grafindo Persada..

Wahyudi. 1996. Manajemen Strategik Pengantar Proses Berpikir Strategik, Jakarta: Binarupa Aksara. 
78 | Wilda Arif

HALAMAN INI SENGAJA DIKOSONGKAN 